\title{
Cultura mestiza y regímenes estéticos de la vida cotidiana. El ethos barroco de Bolívar Echeverría*
}

Fecha de entrega: 5 de noviembre de 2018

Fecha de evaluación: 14 de diciembre de 2018

Fecha de aprobación: 31 de enero de 2019

\author{
Román Santiago Artunduaga Narváez**
}

\section{Resumen}

El presente artículo, inspirado en Bolívar Echeverría, analiza la realidad capitalista latinoamericana como "hecho histórico inevitable" resultado del contacto cultural iniciado en la Colonia española. Sostenemos la tesis según la cual la condición culturalmente ambigua del mestizo colonial hispanoamericano se materializó en una "voluntad de forma" aplicada a la vida cotidiana, que aunque pareciera reproducir los fines instrumentales de la Modernidad centroeuropea, aporta a su superación mediante el establecimiento de una Modernidad otra, donde el yo es integrado al nosotros. Con este propósito abordaremos la casta del mestizo desde cuatro enfoques históricos secuenciales: la inicial ambigüedad cultural del mestizo colonial, la recomposición identitaria de la población mestiza, la Modernidad otra y los regímenes estéticos de la vida cotidiana.

* El texto refiere a los estudios que el autor ha desarrollado sobre el decir estético y la filosofía latinoamericana, tratados especialmente a partir del problema de la identidad, asi como el de la tecnología en relación con el capitalismo y la educación. Citar como Artunduaga Narváez, J. S. (2019). Cultura mestiza y regímenes estéticos de la vida cotidiana. El ethos barroco de Bolivar Echeverría. Cuadernos de Filosofia Latinoamericana, 4O(120), 55-68. DOI: 10.15332/25005375/5376

* Licenciado en Filosofía y Lengua Castellana y magíster en Filosofía Latinoamericana de la Universidad Santo Tomás. Doctor en Filosofia de la Universidad de Salamanca (España). Docente investigador de la Universidad Nacional Abierta y a Distancia. Correo electrónico: romanartunduaga@gmail.com 
Palabras clave: mestizaje, periodo colonial, capitalismo, pensamiento histórico.

\section{Mestizo culture and aesthetic regimes of everyday life. The baroque ethos of Bolivar Echeverria}

\section{Abstract}

This article, inspired by Bolívar Echeverría, analyzes Latin American capitalist reality as an "inevitable historical fact" resulting from the cultural contact initiated in the Spanish Colony. We hold the thesis that the culturally ambiguous condition of the Hispanic-American colonial mestizo materialized in a "will of form" applied to everyday life, which although it seems to reproduce the instrumental purposes of Central European Modernity, contributes to its overcoming by establishing the other Modernity, where the self is integrated into us. For this purpose, we will approach the mestizo caste from four sequential historical approaches: the initial cultural ambiguity of the colonial mestizo, the identity recomposition of the mestizo population, the other Modernity and the aesthetic regimes of daily life.

Keywords: Miscegenation, colonial period, capitalism, historical thinking.

No olvidarse de los acontecimientos pasados

lo convierte a uno en dueño de los futuros.

Memorias históricas 


\section{Introducción}

El proceso de mestizaje es una construcción histórica que va más allá de la violenta dominación física de principios del siglo xvi, los callejones sin salida del problema racial y su uso como tema clave en la comprensión de las dinámicas poblacionales de la América hispana en el periodo colonial. Debe entenderse en cambio como una creación cultural: la asimilación de una perspectiva múltiple sobre el mundo de la vida que - entronizada en el ser latinoamericano - es un factor material en la comprensión de las dinámicas sociales subsiguientes. Asimismo, el mestizaje ha sido el tema preferido para justificar aspectos percibidos como herencias negativas de la cultura latinoamericana, surgidas a su vez de una imagen idealizada de las culturas originarias. Esta perspectiva negativa tiene su justificación histórica: Guamán Poma de Ayala, en su Nueva crónica y gobierno de las Indias de 1613, deja entrever su rechazo a la tradición hispánica, representada por el mundo urbano colonial, precisamente porque percibe en el proceso de mestizaje la desaparición de la población autóctona (Kagan, 2003).

Las ideas de mestizo y mestizaje en cuanto construcciones históricas rehúsan una delimitación espacio-temporal. El mestizaje es "el gran fenómeno demográfico y humano [...] ocurrido en todas las latitudes donde habita el hombre" (Carrión, 2006, p. 375). En efecto, en el plano histórico el mestizaje es un acontecimiento anterior y posterior a la aventura ultramarina hispánica de finales del siglo xv. Los españoles vascos, andaluces, extremeños y castellanos que llegaron al Nuevo Mundo eran a su vez el resultado de un largo proceso de contacto cultural.

La era de las indeterminaciones, las fronteras difusas de la realidad y el pensamiento, requiere conceptos de análisis de naturaleza filosófica que consideren la complejidad fáctica y contrafáctica de la existencia social. En este sentido, para la comprensión de los fenómenos sociales de escala planetaria es importante la categoría mestizaje por cuanto supone la convivencia y contacto continuo o discontinuo entre distintas construcciones humanas cuyos límites escapan a la definición. Ofrece a las claras el esquema general desde donde se puede acceder a la cultura. Significa la disolución del aislamiento originario que permite el ingreso de cada individualidad social a una unidad espiritual mucho más amplia: el ámbito de la historia universal. En la historia concreta sucede algo semejante: la vida de las culturas comprende procesos 
de imbricación, entrecruzamiento, intercambio de elementos materiales y de distintos códigos, que en lugar de negar, marcan sus diferentes identidades (Echeverría, 2000, p. 38).

También el pensamiento histórico en alturas filosóficas depende de la visión de totalidad que le permite diferenciar la explicación histórica de la mera conjetura. En efecto, el historiador, como explorador de la realidad sociocultural en cuanto causada, ha de recurrir a un aparato terminológico que simbolice relaciones y acciones afirmativas, preventivas, prohibitorias y posicionales para imponer una estructura de sentido a los hechos en virtud de una visión panorámica de los procesos socioculturales.

Por lo tanto, recurrimos en este trabajo a los conceptos interrelacionados de interpretación intercultural, poder de definición y mestizo colonial como categorías puente. La totalidad del mundo mestizo confiere el contenido material cohesionante que salva a la historia del formalismo tautológico. Sin mestizos no hay historia, como tampoco cultura. Nuestro propio idioma es mestizo. En el caso hispanoamericano constituye "una categoría social estamentaria compuesta por los hijos de españoles y de indígenas: generalmente el padre es español y la madre natural" (Bernand, 2001, p. 106). Comprende además la unión de dos mundos distintos para formar un tercero. En efecto, en torno al mestizaje el mundo ibero conecta con la cultura europea y con el Nuevo Mundo para establecer la América hispanolatina. El mestizo es, por tanto, una "categoría puente" cuyo destino es unir lo que la geografía y las peripecias de la vida habían separado. El mestizo, como categoría de compresión cultural, surge de una "interpretación intercultural", esto es, de la capacidad de un grupo humano de encontrar similitudes y diferencias para "definir" lo que se le presenta como extraño. Los europeos en su larga historia habían alcanzado aquella interpretación intercultural necesaria para establecer su identidad y su "poder de definición" (Frey, 2002). Los griegos, por ejemplo, se identifican como cultura griega (hellenikón) gracias a su contacto con los persas, definidos como los bárbaros: concepto que les sirve como un "espejo en el cual mirarse para distinguirse a sí mismos" (Fontana, 2000).

El poder de definición está a la base de la violencia simbólica ejercida por una civilización sobre otra y gravita sobre la historia y el desarrollo de los pueblos "reducidos" a la subalternidad. Así, se convierte en una clave de comprensión del ingreso de la América hispanolatina y España a la Modernidad pues como es señalado: 
Si la Modernidad comienza al final del siglo xv, con un proceso renacentista premoderno, y de allí se pasa al propiamente moderno en España, Amerindia forma parte de la "modernidad" desde el momento de la conquista y la colonización (el mundo mestizo en América Latina es el único que tiene tanta edad como la Modernidad) ya que fue el primer bárbaro que la Modernidad necesitaba en su definición. (Dussel, 2011, p. 63)

España se sabe (se define), por tanto, moderna, y con ello se concibe como una parte de Europa por cuanto pudo reducir las diferencias de los otros a la escala de valores de la cultura cristiana centroeuropea.

\section{La ambigüedad cultural del mestizo colonial}

El poder de definición surgido de la "interpretación intercultural” se nutre de los rasgos de personalidad psicológica de las colectividades, surgidos a su vez del choque de culturas. El mestizaje - lejos por fortuna de las deslucidas discusiones en torno a la raza - se halla vinculado a la dualidad de horizontes culturales que deviene en la "radical inseguridad" del mestizo hispanoamericano. Al ser hijo de dos culturas tan diferentes el mestizo colonial está al borde de un precipicio, temiendo "caer", según él, al abismo de la civilización negada; pero tampoco se puede aferrar al mundo de su padre blanco pues este lo rechaza como parte de su autoafirmación. Se sigue de todo esto que no es menor la inseguridad mestiza que la radical inestabilidad identitaria del hombre moderno: los dos son convocados violentamente a tomar partido entre la tradición y la ruptura. No quiere el mestizo colonial negar sin más el mundo de su madre indígena, sino aquella debilidad o inferioridad que lo constituyó en víctima de una sociedad patriarcal. Falsamente desea recobrar la fuerza perdida asumiendo los valores del mundo representado por el padre blanco.

A partir de esa estrategia de supervivencia anímica se explica la rápida dominación española de principios del siglo Xvi y su perdurabilidad hasta principios del xIX. Aquel sentimiento de inferioridad no es caprichoso, obedece a la concepción aprendida del mundo indígena como una civilización endemoniada, que debía ser superada por obra de la evangelización. "El indígena fue conceptuado en definitiva como una realidad histórica en estado de mera potencia que debería actualizarse mediante la incorporación del indio a la cultura europea y en todo caso, al cristianismo" (O’Gorman, 2011, p. 71). La discusión sobre la posibilidad de que los indígenas fueran ordenados 
sacerdotes refleja aquella visión peninsular de la civilización originaria: faltos de autoridad, proclives a la embriaguez, ineptos para el trabajo intelectual, para el régimen de las almas y para el celibato (Ricard, 2017).

La existencia del mestizo, a ojos del español peninsular de los siglos XVI y XVII, obedece a la "debilidad moral" del conquistador, seducido por un ambiente viciado ajeno sus intereses puramente religiosos. La espesura y variedad "monstruosa" de la fauna y flora junto al desenfado de los naturales del Nuevo Mundo significaron - en la interpretación intercultural cristiana - la desmesura: la falta de "límite", el lugar donde no puede crecer la virtud. Todo ello lleva sobre sí el mestizo colonial. "Se trata de un ser originado de linajes de calidades distintas" (Bernand, 2001, p. 108). Aquella falta de límite del mundo americano en la interpretación intercultural cristiana justificaría en últimas la aventura indiana. Europa requiere expandir los límites de su mundo conquistando y dominando lo que debió ser integrado pacíficamente. La Conquista y la Colonia fueron coherentes con la mentalidad del momento. Siguiendo el aristotelismo imperante en la intelectualidad tardomedieval, se entendió que el conocimiento es posible por la "forma", que supone delimitar un contenido de lo que "no es" y universalizarlo para el pensamiento. La materia concretiza la forma, pero la materialidad de los seres es objeto de los sentidos y no del pensamiento ${ }^{1}$.

El ethos barroco - en su afán de dar forma para comprender y conquistar- está en la raíz de la identidad del mestizo. Por barroco, escribe Bolívar Echeverría, se debe entender una
voluntad de forma específica, una determinada manera de comportarse con cualquier sustancia para organizarla, para sacarla de cualquier estado amorfo previo o para metamorfosearla; una manera de conformar o configurar que se encontraría en todo el cuerpo social y en toda su actividad. (2013, p. 58)

La España imperial en su proceso identitario se ve forzada a "dar forma", a imponer "límites" a todo aquello que se presenta como ajeno. En ese sentido, la interpretación intercultural cristiana sirve de marco para configurar lo diferente, surgido - algunas veces de modo pacífico, otras, violento- a partir del contacto con culturas diferentes.

1 Nos referimos al momento platónico de Aristóteles, trascendental (Jaeger, 1999), reflejado a partir de los célebres traductores y comentaristas, que por obvias razones no contaban con la obra completa del Estagirita ni tenían un aparato critico tan sofisticado como en la actualidad. 
Las victorias europeas en el plano político y militar sobre los indígenas otorgarían aquella potencia definitoria: la de imponer un límite, una distancia con respecto a los otros. En ese mismo sentido, la filosofía y la ciencia europea aportarán a la Modernidad la idea de universalidad mediante un "proceso de simplificación por racionalización del mundo de la vida, de sus subsistemas económico, político, cultural, religioso, etc.” (Dussel, 2011, p. 60). Las célebres discusiones acerca de la racionalidad del indio surgen precisamente de los equívocos en los que incurriría la interpretación intercultural vigente, que neutraliza paradójicamente a la misma acción evangelizadora.

No obstante, el mestizo colonial, en cuanto inaprensible en una definición consistente, es libre para hacer variaciones sobre su identidad. A diferencia de los zambos, indígenas, negros y mulatos, no tiene un amo a quien servir; su vida errante y aventurera no radica en la casa señorial; al igual que su padre blanco está exonerado de pagar impuestos, de modo que trabaja tan solo para su propia subsistencia; sobre su cabeza solo tiene al Rey y al Cielo. "Los mestizos no constituyen una 'nación' distinta ni poseen emblemas particulares [...] se reducen a un conjunto de individuos, y solo se puede uno acercar a ellos mediante el análisis de sus itinerarios personales" (Bernand, 2001, p. 123). Viven apartados del control social del pueblo y la comunidad, de ahí que puedan "elegir" a qué cultura plegarse, y eligen en cambio resignificar para sí todo aquello que le era distante y valioso al español peninsular.

En definitiva, en la América Latina colonial se genera un ethos social propio de las clases bajas y marginales de las ciudades mestizas de los siglos XVII y XVIII (Echeverría, 2008). Una Modernidad otra esencialmente trasgresora, que sirvió para la supervivencia de los indígenas de finales del siglo xv y que con el tiempo constituyó "un modo de ser en el mundo" resultante de la experiencia devastadora de la razón instrumental y de la destrucción del mundo amerindio. Desde este enfoque, por consiguiente, se debe comprender la propuesta de modernidad del mundo novohispano; modernidad que no repite la europea, sino que la re-crea; establece un modelo completamente diferente:

Jugando a ser europeos, no copiando las cosas o los usos europeos, sino mimetizándose, simulando ser ellos mismos europeos, es decir, repitiendo o "poniendo en escena" lo europeo, los indios asimilados montaron una muy peculiar representación de lo europeo. (Echeverría, 2008, p. 9) 


\section{La recomposición identitaria: "La puesta en escena absoluta"}

El nuevo modo de ser del mestizo respecto de lo propio y lo ajeno hunde sus raíces en el otro lado del Atlántico. En efecto, la idea de "acomodarse" a la visión dominante viene por vía paterna. La cultura española, tardomedieval, confiere el marco de referencia de esa acción recreadora:

Este artefacto cultural define, así, tres grupos según su supuesta función social: la nobleza (los bellatores, defensores de la cristiandad), el clero (los oratores, que rezan para idéntico fin) y los demás (los laboratores, que trabajan para mantenerlos a todos). (Soria, 2003, p. 433)

Al negársele pertenecer al alto clero o a la nobleza el mestizo viene a formar parte de los laboratores. La aceptación del cristianismo lo vincula ipso facto a aquel cuerpo social:

Se trata, claro está, de la pertenencia al mundo ibérico y dependencia de su cultura y modo de ser. Como rama de ese tronco, participa, como algo entrañablemente suyo, en el programa de vida tradicionalista, absolutista, católico y enemigo de la Modernidad. (O’Gorman, 2011, p. 75)

Sin embargo es precisamente en ese escenario donde se realiza la representación creadora de la otra dimensión "imaginaria" de lo cualitativo.

En España,

la nobleza era el corazón de la sociedad, la aspiración de toda persona, familia o grupo, la ambición de todos los que podían permitirse los importantes dispendios que costaba acceder a ella. Vivir como un noble, ostentar sus símbolos y compartir sus modelos de comportamiento fue en multitud de ocasiones el leit motiv de las gentes que, de una forma u otra, pertenecían a las clases dirigentes de la monarquía hispánica. (Soria, 2003, p. 435)

Si bien el mestizo, por ley, no podía hacer parte del gobierno, se acercaría mucho mimetizándose en las costumbres del estatus nobiliario, pero recreándolas en conformidad con la novedad de su existencia. Una de aquellas costumbres, heredadas de la 
España imperial, era la exclusión de buena parte de los cuerpos sociales que por una razón u otra no se ajustaban a las rígidas normas de una sociedad enferma de honor (Soria, 2003, p. 435). Sin embargo, el éxito poblacional de los mestizos matizó aquel brillo imperial contradiciendo el menosprecio y la marginación hacia los "inferiores", los laboratores. El mestizo, en cambio, superó la segregación económica, étnicoreligiosa, jurídica y de género, y en este sentido se constituyó la Modernidad otra. La nobleza no radicará en separarse, sino en multiplicarse para crear familias numerosas, lo que resultaría en beneficios económicos y de influencia para estas mismas. El mestizo no reprodujo sin más el mundo cultural del dominador, como se ha abordado actualmente en los estudios culturales coloniales o como lo supone la habitual representación del "resentido" - rechazado por las dos culturas y que se queda en la mera indeterminación de un "borroso elemento de la clase media", como lo señaló en su día el insigne historiador y antropólogo Luis Eduardo Valcárcel (1943)—. Por el contrario, acogemos la sugerencia de José María Arguedas (1998), quien en su obra Formación de una cultura nacional indoamericana exige el estudio de la contribución de los mestizos a la complejidad actual de la vida social.

El mestizo vio además la necesidad de "representar" la cultura del dominador en las costumbres cotidianas, pero transformándolas, modernizándolas, abriéndolas a los otros, y evidenció así el aporte cultural de su madre indígena. El éxito de la conquista y dominación española se debe a que los pueblos originarios de América no habían tenido experiencia del otro como otro, sino que "la otredad que ellos veían en los españoles les parecía una variante de la mismidad o identidad de su propio Yo colectivo, y, por tanto, un fenómeno perfectamente reductible a ella" (Echeverría, 2000, p. 24). En este sentido, la imposibilidad de los naturales de América para aniquilar ontológicamente al invasor, negar su identidad, era coherente con su propia manera integracionista de ver el universo, lo que a su vez permitió la sobrevivencia de los que habrían de aportar al continuum del mestizaje americano. "Los europeos, en cambio, aunque percibían la otredad del Otro como tal, lo hacían solo bajo uno de sus dos modos contrapuestos: el del peligro o la amenaza para la propia integridad" (Echeverría, 2000, p. 24), actitud que como señalábamos líneas antes corresponde más a la premodernidad que a la era moderna.

En Amerindia, por ejemplo, la "representación de la estética cotidiana hispánica”, además de ser la estrategia de obtención de un mejor lugar en el reparto del poder y la riqueza, es un lugar donde sucede la integración creativa de lo diverso, 
la descentralización del sujeto que pasa del yo cartesiano al nosotros. En efecto, la indumentaria es un ejemplo del proceso de mestizaje cultural. En el siglo xvi los ingleses se sorprendieron al encontrar a los cimarrones del palenque de Ballano vestidos a la "española" (Bernand, 2001, p. 116). A esto se suman las transformaciones económicas que hacen que se abandone "la ropa de la tierra", lo que promueve la recomposición identitaria. Al respecto señala Bernand:

En las ciudades, la proliferación de las tiendas de telas, paños, ruanas, lienzos, sedas y terciopelos facilitan la confusión de los estatus. Bernabé Cobo lo dice claramente al describir a los indios de Lima: tan españolados que todos generalmente, hombres y mujeres, entienden y hablan nuestra lengua y en el tratamiento de sus personas y aderezo de sus casas parecen españoles y basta decir para prueba de esto, que entre todos ellos tienen más de ochenta negros esclavos. (2001, p. 116)

El Nuevo Mundo recibe, por tanto, el ethos barroco del momento histórico, lo asimila y acepta, pero con vistas a transmutarlo en una realidad nueva. "Juega" con lo recibido, recrea el mundo del vencedor, del conquistador, y de esta forma lo integra a su cosmovisión. Al cambiar sus vestiduras los indígenas no cambian su cultura, antes bien, la recrean, lo que demuestra que la identidad no se trata de un pasado fosilizado que hay que reconstruir de las cenizas, sino de un hecho humano en la historia, sujeta siempre al cambio y que hay que comprender en constante movimiento.

El Nuevo Mundo mestizo resignifica al Viejo. Hispanoamérica actualiza la vieja Europa, comprendida hasta entonces como un "modelo plenamente acabado de la realidad histórica o espiritual del hombre” (O’Gorman, 2011, p. 55). En este sentido, no existe la dicotomía manifestada por O’Gorman según la cual el mundo hispanoamericano, proyecto de vida en potencia, busca prolongar la vigencia de un proyecto de vida ya actualizado - según el historiador mexicano, "en Iberoamérica el modelo fue una entelequia; para angloamérica, una utopía” (2011, p. 73) - . Por el contrario, debemos comprender, junto a Bolívar Echeverría, la génesis de un Nuevo Mundo a partir de la agonía de dos civilizaciones.

La creatividad de la "puesta en escena" reivindica la vida sobre las cenizas del mundo destruido para construir una nueva civilización sobre la misma vida. En este sentido, América Latina correría por los caminos de una modernidad no capitalista. 
La Modernidad es un producto europeo; pero sus distintas versiones obedecen al ethos barroco que, como voluntad de forma, busca transformar la materia dada para manifestar una vitalidad concreta (Dussel, 2012). La Modernidad otra, no capitalista, resultado del mestizaje cultural, constituye, en términos de Stefan Gandler (2000), la evidencia en Bolívar Echeverría de lo genuinamente moderno que rechaza la actitud premoderna de la pureza cultural. Supone además una relación con el cosmos, con la naturaleza, no depredadora, sino creadora de un derecho a disfrutar la casa común.

\section{Modernidad otra y regímenes estéticos de la vida cotidiana}

El capitalismo se inserta en la cultura mestiza mediante la imposición del valor de uso en las relaciones sociales. Aquel valor constituye la forma objetiva del hecho capitalista al que se somete la "valorización del valor abstracto" (Echeverría, 2000, p. 38). En otras palabras, se trata de un modo de relación económica que alcanza la consistencia suficiente para convertirse en un ethos cultural. Por su carácter de "hecho histórico inevitable" la realidad capitalista actualiza los códigos lingüísticos, pautas de conducta y simbolizaciones de lo otro. Desde esta lógica la estetización de la vida cotidiana es la pretensión barroca de la Modernidad capitalista de dar forma al mundo de la vida como complemento de la forma dada al territorio. La forma, como decíamos, supone un límite que permite identificar un contenido, el cual a su vez remite a un afuera, por lo que es una "negación-afirmante". La línea de la forma señala un adentro y un afuera. De esta manera, afirma Bolívar Echeverría, la Modernidad capitalista busca su identidad mediante la negación del otro, recuperando la universalidad del hombre mediante la negación de la humanidad concreta:

El desarrollo de la economía mundial realmente existente, es decir, basada en la unificación tecnológica del proceso de trabajo a escala planetaria, vuelve impostergable la hora de una universalización concreta de lo humano. Cada vez se vuelve más evidente que la humanidad del "hombre en general" solo puede construirse con los cadáveres de las humanidades concretas. (Echeverría, 2013, p. 27)

Por el contrario, la Modernidad otra reafirma la humanidad concreta mediante la resignificación de la estética cotidiana aportándole un contenido emancipador y de 
reconocimiento. En ese sentido, el mundo mestizo vigente escapa a la determinación histórica del capitalismo imperante. Hay que recordar que el declive de las civilizaciones antiguas está asociado a la capacidad de absorber a otras culturas; en cambio, la asimilación de lo ajeno es la condición de la afirmación de lo propio (Echeverría, 2000).

Es preciso además reconocer aquellos regímenes estéticos de la vida cotidiana que fortalecen la inserción del valor de uso en las relaciones humanas. Espacios prohibitorios del consumo que enfatizan la distancia, la reafirmación del yo sobre el nosotros. La auténtica democracia se apoya en los espacios de creatividad de las colectividades. Por el contrario, el régimen actual del capitalismo impone un consumo de la imagen soportado en el "hambre de forma" del hombre moderno en cuanto individuo.

El universalismo abstracto de la Modernidad centroeuropea es un proceso de homogenización de todos los niveles de la vida, que construye sujetos y subjetividades "legibles" y crea espacios higiénicamente puros, libres de sorpresas, ambivalencias y conflictos (Bauman, 2001). Espacios que afincan la diferencia e impiden la normal socialización con lo diverso. La imagen estándar, en cuanto marca de clase, que produce y reproduce la industria es asimilada por las personas como lo deseable, lo estéticamente correcto. Pero a su vez se reproduce por los medios de comunicación la “estética de la miseria”, de la tierra de nadie, el conciudadano indeseado, la atmósfera de la barbarie. Este hecho capitalista, históricamente inevitable por la emergencia de lo barroco, en lugar de negarse debe ser recreado en la construcción espontánea del mundo de la vida, convertido en segunda naturaleza por el ethos que asegura la armonía indispensable de la existencia cotidiana (Echeverría, 2000, p. 38). De lo contrario, los actuales regímenes estéticos del capitalismo sumirán a los individuos en la soledad de la existencia, en la incapacidad de negociar valores, de asumir, como señala Bauman (2001), la madurez moral que consiste en "desear conocer lo desconocido, [...] sentirse incompletos sin una cierta anarquía en sus vidas, que saben amar la alteridad a su alrededor" (Echevarría, 2000, p. 64).

\section{Conclusión}

La globalización en que vivimos es una época de contacto entre culturas, que como en otros momentos de la historia ha representado varios retos a la vida del hombre. Uno de ellos, quizás el más importante, es superar la amenaza de la eliminación de las culturas locales. Contra este fenómeno previsible debemos buscar en el pasado para 
encontrar el punto de inflexión que explica el presente y tomar las decisiones que sean pertinentes. Con estos propósitos encontramos que el capitalismo, a partir del ethos moderno, establece un ordenamiento de la cotidianidad, y con este entroniza un orden valorativo que soporta aquel régimen de finalidades emanado de la universalidad de la civilización occidental. Sin embargo, del mismo pasado podemos sacar la lección de que no estamos predestinados a padecer la historia, sino que debemos buscar en la cultura popular la superación de ese poder de definición que durante siglos se le ha entregado al opresor. Nos referimos a la posibilidad de la Modernidad otra, la cual reafirma la humanidad concreta mediante la resignificación de la estética cotidiana impuesta, las costumbres, las fiestas, el mundo valorativo del latinoamericano, de un manifiesto contenido emancipador. Lo que se debe seguir poniendo en cuestión es la posibilidad de coexistencia de varios universalismos: la posibilidad de una civilización diferente de la establecida, que no se encuentra excluyendo, sino integrando. Este propósito no es inédito en la historia latinoamericana. Los jesuitas a partir del siglo XVIII, nos dice Bolívar Echeverría (2000), habrían buscado establecer una modernidad alternativa que fue detenida por la "mala modernidad". Nuestro deber histórico es hacerla realidad para el porvenir.

\section{Referencias}

Arguedas, J. M. (1998). Formación de una cultura nacional indoamericana. México: Siglo XXI.

Bauman, Z. (2001). La globalización. Consecuencias humanas. México: FCE.

Bernand, C. (2001). Mestizos, mulatos y ladinos en Hispanoamérica: un enfoque antropológico de un proceso histórico. En M. L. Portilla (coord.), Motivos de la antropología americanista. Indagaciones en la diferencia. (pp. 105-131). México: FCE.

Carrión, B. (2006). El mestizaje y lo mestizo. En L. Zea (coord.), América Latina en sus ideas (pp. 375-400). México: Siglo xxI.

Dussel, E. (2011). 1492: El encubrimiento del otro. El origen del mito de la modernidad. Bogotá: Anthropos.

Dussel, E. (2012). Modernidad y ethos barroco en la filosofía de Bolivar Echeverría. Recuperado de https://www.fuhem.es/media/ecosocial/file/Boletin\%20ECOS/ Boletin\%2016/modernidad.pdf 
Echeverría, B. (2000). La modernidad de lo barroco. México: Era.

Echeverría, B. (2008). El ethos barroco y los indios. Revista de Filosofía "Sophia", 2, pp. 6-11.

Echeverría, B. (2013). La Modernidad de lo barroco. Mexico: Era.

Fontana, J. (2000). Europa ante el espejo. Barcelona: Austral.

Gandler, S. (2000). Mestizaje cultural y ethos barroco. Una reflexión intercultural a partir de Bolívar Echeverría. Signos Filosóficos, 1(3), 53-73.

Jaeger, W. (1999). Aristóteles. México: FCE.

Kagan, R. L. (2003). Entre dos mundos: la ciudad en la "Nueva crónica” de Guamán Poma de Ayala. En C. A. González y E. Vila (comps.), Grafías del imaginario. Representaciones culturales en España y América (Siglos XVI y XVIII) (pp. 378-393). México: FCE.

O’Gorman, E. (2011). Conciencia de la historia. Ensayos escogidos. México: FCE.

Ricard, R. (2017). La conquista espiritual de México. Ensayo sobre el apostolado y los métodos misioneros de las órdenes mendicantes en la Nueva España de 1523-1524 a 1572. México: FCE.

Soria, E. (2003). La sociedad en los siglos XVI y Xviı. En R. García (coord.), Historia de España siglos XVI y XVII. La España de los Austrias (pp. 433-465). Madrid: Cátedra.

Valcárcel, L. E. (1943). Historia de la cultura antigua del Perú. Lima: Museo Nacional. 